\title{
Analytical validation of the new version of the Liaison N-Tact PTH assay
}

\author{
Etienne Cavalier ${ }^{1, *}$, Pierre Delanaye ${ }^{2}$, Agnès \\ Carlisi $^{1}$, Jean-Marie Krzesinski ${ }^{2}$ and Jean-Paul \\ Chapelle $^{1}$ \\ ${ }^{1}$ Department of Clinical Chemistry, University \\ Hospital of Liège, University of Liège, Belgium \\ 2 Department of Nephrology, University Hospital of \\ Liège, University of Liège, Belgium
}

\begin{abstract}
We performed analytical validation of the new version of the Liaison N-Tact PTH (parathormone) assay according to NCCLS guidelines and compared this new generation of reagent with the Roche Elecsys PTH assay. We showed that this new version is a sensitive and precise method with good recovery. Significant carryover was observed, but with limited clinical implications. We demonstrated that the new version of the Liaison PTH is in reasonably good agreement with the Roche Elecsys PTH assay, and as we observed no differences in a hemodialyzed population, moving from one method to the other should not affect the daily follow-up of patients. However, one should be cautious with the highest values ( $>500 \mathrm{pg} / \mathrm{mL}$ ). We established reference intervals of $12-54 \mathrm{pg} / \mathrm{mL}$ for the Liaison and $14-52 \mathrm{pg} / \mathrm{mL}$ for the Elecsys assay.

Clin Chem Lab Med 2007;45:105-7.
\end{abstract}

Keywords: analytical validation; hemodialyzed patient; parathormone; reference interval.

Parathormone (PTH), an 84-aa polypeptide hormone synthesized and secreted by the parathyroid glands, is a major regulator of bone metabolism and calcium homeostasis. PTH determination is frequently prescribed in clinical routine to manage renal osteodystrophy in patients with chronic kidney disease (CKD) or in patients with disorders of mineral metabolism. The objective of this investigation was to evaluate the analytical performance of the new version of Liaison $\mathrm{N}$-Tact PTH assay (DiaSorin, Saluggia, Italy) according to the NCCLS guidelines (1). We also compared this new generation of reagent with the Roche Elecsys PTH assay (Roche Diagnostics, Mannheim, Germany) and established reference intervals for the two kits.

*Corresponding author: Dr. Etienne Cavalier, Service de Chimie Médicale, CHU de Liège, Domaine du Sart-Tilman, 4000 Liège, Belgium

Phone: +32-4-3667692, Fax: +32-4-3667691,

E-mail: etienne.cavalier@chu.ulg.ac.be
The study was performed using blood samples collected in serum gel separators with a clot activator (Terumo, Haasrode, Belgium).

The Liaison ${ }^{\circledR} \mathrm{N}$-Tact PTH assay is a chemiluminescence immunoassay (CLIA) using a first antibody directed against the $\mathrm{N}$-terminal (aa $1-34$ ) region of the molecule conjugated to an isoluminol derivative and a second antibody directed against the C-terminal (aa 39-84) region immobilized on magnetic particles. During incubation, PTH binds to the solid phase and is subsequently bound by isoluminol-conjugated antibody. After incubation, the unbound material is removed with a wash cycle. The starter reagent is then added and a flash chemiluminescent reaction is initiated. The light signal is measured by a photomultiplier as relative light units (RLU) and is proportional to the concentration of PTH present in the samples.

The Roche intact PTH assay is an electrochemiluminescence method based on a sandwich reaction: one biotinylated monoclonal anti-PTH antibody is directed against the N-terminal (aa 26-32) portion of the molecule (2) and a second monoclonal antibody, labeled with ruthenium, recognizes the C-terminal fragment (aa 38-84). The inter-assay precision on an Elecsys 1010 platform is $<5 \%$ at both 46 and 341 $\mathrm{pg} / \mathrm{mL}$.

We assessed the intra- and inter-assay precision at two levels (41 and $129 \mathrm{pg} / \mathrm{mL}$ ) using 15 determinations per level, as well as the functional sensitivity (defined as the lowest PTH concentration giving a CV $<20 \%$ in an inter-assay determination). Intra- and inter-assay $\mathrm{CVs}$ were $<10 \%$ and the functional sensitivity was found to be $12 \mathrm{pg} / \mathrm{mL}$.

Recovery was determined according to NCCLS guideline EP-6P: five low-concentration serum samples and five high-concentration samples were assayed a minimum of five times to establish levels in neat serum. These samples were then mixed at ratios of 1:3, 1:1 and 3:1 and re-assayed in replicates of three. The results are excellent, as listed in Table 1.

We diluted two patient samples (1348 and 1220 $\mathrm{pg} / \mathrm{mL}) 1: 2,1: 4,1: 8,1: 16,1: 32,1: 64$ and 1:128 with $0.05 \mathrm{M}$ phosphate buffer $(\mathrm{pH} 7.5)$ containing $0.9 \%$ $\mathrm{NaCl}$. The results were then plotted and the expected vs. observed values analyzed by least-squares linear regression. The dilutions resulted in a linear plot (Figure 1) and the regression equation was: measured $=0.9951$ (expected) +6.0 , with a correlation coefficient of 0.99 .

We spiked four patient samples of previously determined PTH concentrations with human PTH 1-84 
Table 1 Recovery for the Liaison PTH assay.

\begin{tabular}{llcc}
\hline Sample & $\begin{array}{l}\text { Concentration } \\
\text { expected, pg/mL }\end{array}$ & $\begin{array}{l}\text { Concentration } \\
\text { observed, pg/mL }\end{array}$ & $\begin{array}{l}\text { Recovery, } \\
\%\end{array}$ \\
\hline Sample 1 & & 7 & \\
Low neat & & 457 & \\
High neat & & 129 & 108 \\
3L:1H & 119 & 245 & 106 \\
1L:1H & 232 & 349 & 101 \\
1L:3H & 344 & & \\
Sample 2 & & 5 & \\
Low neat & & 110 & 84 \\
High neat & & 26 & 84 \\
3L:1H & 31 & 48 & 83 \\
1L:1H & 57 & 70 & \\
1L:3H & 84 & 18 & \\
Sample 3 & & 219 & 102 \\
Low neat & & 70 & 83 \\
High neat & 69 & 98 & 107 \\
3L:1H & 119 & 181 & \\
1L:1H & 169 & & \\
1L:3H & & & \\
\hline & & & \\
\hline
\end{tabular}

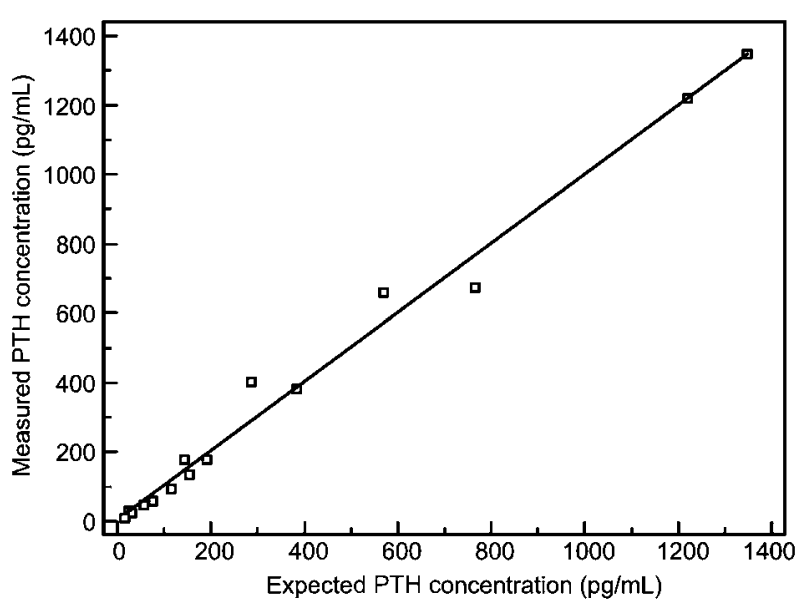

Figure 1 Dilution linearity of the Liaison PTH assay. Least-square linear regression of the measured vs. expected values is $y=0.9951 x+6.0(r=0.99)$.

(Bachem, Bubendorf, Switzerland) at concentrations of $6,13,33$ and $65 \mathrm{pg} / \mathrm{mL}$. The mean recovery was 95\% (range $87-101 \%$ ).

To assess the hook effect, we spiked PTH 1-84 (Bachem) into patient samples at levels of 783,000 $-7.8 \mathrm{pg} / \mathrm{mL}$ in six-fold steps. Raw relative light unit (RLU; background normalized light output) readings were used, as the instrument does not report concentrations $>2000 \mathrm{pg} / \mathrm{mL}$. The raw RLU response to spiked PTH was linear between 250 and $6300 \mathrm{pg} / \mathrm{mL}$, as judged by $<10 \%$ deviation from predicted results based on extrapolation of the calibration curve. At concentrations $>6300 \mathrm{pg} / \mathrm{mL}$, the response curve flattened. A hook was observed for a spiked concentration of $783,000 \mathrm{pg} / \mathrm{mL}$.

We evaluated possible carryover by placing four consecutive blank samples after a patient sample containing a high level of PTH $(1273 \mathrm{pg} / \mathrm{mL})$; the first blank sample was measured at a significant level of $6 \mathrm{pg} / \mathrm{mL}$, while the other samples were considered as negative $(<2.5 \mathrm{pg} / \mathrm{mL})$.
We generated fasting reference intervals for the Liaison PTH and Roche Elecsys PTH assays using 60 patients (11 male, 49 female) aged 23-85 years with $25-\mathrm{OH}$ vitamin D levels $>50 \mathrm{nmol} / \mathrm{L}$, glomerular filtration rate evaluated by the MDRD (3) formula $>60$ $\mathrm{mL} / \mathrm{min} / 1.73 \mathrm{~m}^{2}$, negative rheumatoid factor (RF) and total calcium level within the laboratory reference range. The reference interval was determined to be 12-54 pg/mL for the Liaison and $14-52 \mathrm{pg} / \mathrm{mL}$ for the Roche Elecsys assay. We found no age- or genderrelated differences.

We compared the Liaison second-generation N-Tact PTH assay with another chemiluminescent method, the Roche Elecsys PTH, using 185 consecutive nonhemodialyzed patients with PTH levels of 12-208 $\mathrm{pg} / \mathrm{mL}$. Data were analyzed by Passing-Bablok regression and Bland-Altman plots. The Liaison assay showed good agreement with the Elecsys method $(r=0.93, \mathrm{Cl} 0.91-0.95$; slope 1.16, Cl 1.12-1.21; intercept $-4, \mathrm{Cl}-6$ to -2 ). The Bland-Altman plot showed a mean difference of $-4.3 \mathrm{pg} / \mathrm{mL}$ and an inflexion point near the upper reference interval $(54 \mathrm{pg} / \mathrm{mL})$, with a trend for Liaison to read higher than Elecsys at high concentrations and lower at low concentrations (Figure 2). The Wilcoxon test showed no differences between the Liaison and Elecsys assays in patients with normal PTH (28 vs. $27 \mathrm{pg} / \mathrm{mL}, \mathrm{n}=96$ ), but in patients with $\mathrm{PTH}>54 \mathrm{pg} / \mathrm{mL}$, the Liaison results were significantly higher than the Elecsys results (81 vs. $71 \mathrm{pg} / \mathrm{mL}, \mathrm{n}=89, \mathrm{p}<0.0001)$.

We also compared the two methods in 71 hemodialyzed patients with PTH levels ranging from 15 to $824 \mathrm{pg} / \mathrm{mL}$. In this population, no difference was observed between the median values (Elecsys 276 $\mathrm{pg} / \mathrm{mL}$ and Liaison $289 \mathrm{pg} / \mathrm{mL}, \mathrm{p}>0.05)$. The BlandAltman plot showed a mean difference of $39 \mathrm{pg} / \mathrm{mL}$, but a discrepancy was observed in the results for the three patients presenting the highest PTH levels (Liaison results 685,627 and $694 \mathrm{pg} / \mathrm{mL}$, Elecsys results 1269, 1306 and $1313 \mathrm{pg} / \mathrm{mL}$, respectively) (Figure 3). However, the results were in good agreement (slope $0.89, \mathrm{Cl} 0.89-0.99$; intercept $-11.4, \mathrm{Cl}-1.7$ to -22.6 ), with $r=0.89(0.83-0.93)$.

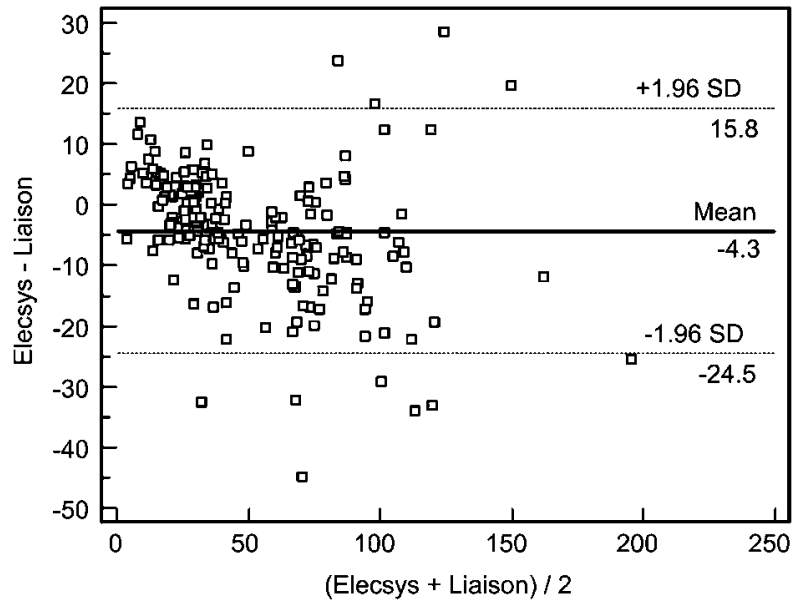

Figure 2 Bland-Altman plot for PTH obtained in 185 patients with the Liaison second-generation PTH and Roche Elecsys PTH assays.

Results are given in $\mathrm{pg} / \mathrm{mL}$. 


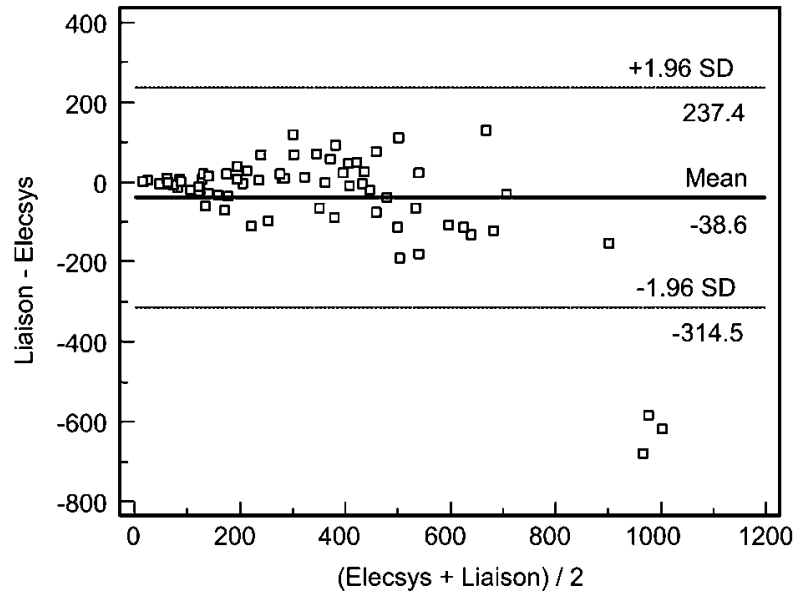

Figure 3 Bland-Altman plot for PTH obtained in 71 hemodialyzed patients with the Liaison second-generation PTH and Roche Elecsys PTH assays.

Results are given in $\mathrm{pg} / \mathrm{mL}$.

In conclusion, our data indicate that the Liaison second-generation PTH assay is a sensitive and precise method. The recovery is good and we observed significant carryover, albeit with limited clinical implications. We demonstrated that the Liaison secondgeneration PTH assay is in reasonably good agreement with the Roche Elecsys PTH assay, but in patients with elevated serum PTH, the Liaison results are higher than the Elecsys results.

It has recently been shown (4) that inter-method variability in PTH measurement can lead to opposite therapeutic decisions in an individual patient, depending on the PTH assay used. Adaptations $(5,6)$ of the K/DOQI guidelines (7) have been suggested, as these recommendations are based on a determination of PTH by the Nichols Allegro PTH assay. As we did not observe any differences in our hemodialyzed population for PTH measured by the Elecsys and Liaison second-generation assays, moving from one method to the other should not affect the daily follow-up of patients. However, caution is required for the highest values (>500 pg/mL). Indeed, in our limited population, the Roche Elecsys PTH assay seemed to overestimate these results compared to the Liaison assay and the N-Tact PTH SP IRMA (DiaSorin) (data not shown). We have no clear explanation for the discrepancies observed in these patients. This issue should be studied in a larger sample of hemodialyzed patients with severe hyperparathyroidism.

\section{References}

1. Gochman N. NCCLS and voluntary consensus standards for the clinical laboratory. Clin Chem 1975;21:1531-3.

2. D'Amour P, Brossard JH, Rakel A, Rousseau L, Albert C, Cantor T. Evidence that the amino-terminal composition of non-(1-84) parathyroid hormone fragments starts before position 19. Clin Chem 2005;51:169-76.

3. Levey AS, Bosch JP, Lewis JB, Greene T, Rogers N, Roth D. A more accurate method to estimate glomerular filtration rate from serum creatinine: a new prediction equation. Modification of Diet in Renal Disease Study Group. Ann Intern Med 1999;130:461-70.

4. Souberbielle JC, Boutten A, Carlier MC, Chevenne D, Coumaros G, Lawson-Boday E, et al. Inter-method variability in PTH measurement: implication for the care of CKD patients. Kidney Int 2006;70:345-50.

5. Souberbielle JC, Fayol V, Sault C, Lawson-Body E, Kahan A, Cormier C. Assay-specific decision limits for two new automated parathyroid hormone and 25-hydroxyvitamin D assays. Clin Chem 2005;51:395-400.

6. Cavalier E, Delanaye P, Krzesinski JM, Chapelle JP. Comparison of Liaison N-tact PTH (Diasorin) and N-tact PTH SP IRMA (Diasorin) in hemodialyzed patients. Clin Chem Lab Med 2005;43:890-1.

7. $\mathrm{K} / \mathrm{DOQ}$ clinical practice guidelines for bone metabolism and disease in chronic kidney disease: Am J Kidney Dis 2003;42(Suppl 3):S1-201.

Received September 6, 2006, accepted October 13, 2006 